Basic Health Sciences

Abstract ID: 90

\title{
Evaluation of the phytochemical content and the use of the essential oil from the leaves of Malaysian Plectranthus amboinicus (lour) spreng as antimalarial in vivo
}

\author{
Norazsida Ramlia $\mid$ Pakeer Oothuman ${ }^{\mathrm{b}} \mid$ Muhammad Taher ${ }^{\mathrm{c}}$ \\ ${ }^{a}$ Kulliyyah of Allied Health Sciences, International Islamic University Malaysia \\ ${ }^{b} K u l l i y y a h$ of Medicine, International Islamic University Malaysia \\ 'Kulliyyah of Pharmacy, International Islamic University Malaysia
}

Introduction: This study was conducted to evaluate the phytochemical contents and antimalarial properties of the essential oils extracted from the leaves of Malaysian Plectranthus amboinicus in mice infected with Plasmodium berghei. Methods: The essential oils were extracted and prepared by using a steam distillation technique and subjected to phytochemical screening by using gas chromatography-mass spectrometry (GC-MS). The antimalarial activity of different extract doses of the essential oil was tested in vivo in ICR (Instritute of Cancer Research) mice infected with Plasmodium berghei (PZZ1/100) during early, established and residual infections. The control groups were treated with distilled water (containing 10\% DMSO, the solvent of the test extracts) and 2 standard drugs: chloroquine and Fansidar. Results: In all, 5 compounds made up $88.34 \%$ of total oil and the major chemical compounds were carvacrol $(85.14 \%)$, thymoquinone $(1.65 \%)$, terpinen-4-ol $(0.70 \%)$, octenol $(0.62 \%)$ and thymol $(0.23 \%)$. Antimalarial assay showed this essential oil as a potential prophylactic agent with the percentage chemosuppression of $45.23 \%, 18.28 \%, 45.38 \%$ and $58.26 \%$, while treated with $50,200,400$ and $1000 \mu \mathrm{L} / \mathrm{kg}$ respectively of essential oil. It also showed a potential as a curative agent with percentage of chemosuppression of $54.10 \%, 47.35 \%, 56.75 \%$ and $65.38 \%$ while treated with the above dose of essential oil. Statistically, no reduction of parasitemia was calculated for suppressive test. Conclusions: The extract has prophylactic and curative effects on P.berghei in mice.

KEYWORDS: phytochemical, toxicity, Plectranthus amboinicus, antimalarial 